\title{
Ultrastructural Characteristics of Experimental Arterial Medial Fibroplasia Induced by Vasa Vasorum Occlusion ${ }^{1,2}$
}

\author{
Vikrom Sottiurai, Ph.D., M.D., William J. Fry, M.D., and James C. Stanley, M.D. \\ Departments of Anatomy and Surgery, University of Michigan Medical School, Ann Arbor, Michigan 48109
}

Submitted for publication November 4, 1977

Arterial fibrodysplasia is a pathologic entity of increasing clinical importance and undetermined etiology. Mural ischemia may be of primary importance as a cause of the most common dysplastic lesion, medial fibroplasia [8]. Recent electronmicroscopic studies of fibrodysplastic human renal arteries by the authors assuciated abnormal vasa vasorum to regions of medial dysplasia. These observations lend indirect support to the tenet that impairment of vessel wall blood supply may be a necessary accompaniment of this disease. The present investigation was undertaken to determine if experimentally induced vasa vasorum occlusion in canine vessels would produce histologic changes of medial fibroplasia. Ultrastructural studies were performed to better define the cellular and subcellular alterations attending this model of arterial fibrodysplasia.

\section{MATERIALS AND METHODS}

Sixteen adult dogs, 19 to $42 \mathrm{~kg}$ in weight, were utilized for study. Iliofemoral arterial segments approximately $5 \mathrm{~cm}$ in length were dissected from surrounding tissues in anesthetized animals (intravenous pentobarbital, $30 \mathrm{mg} / \mathrm{kg}$ ). Care was taken to avoid unnecessary disturbance of adventitial structures. Vessels were isolated proximally and distally with polyethylene loops

\footnotetext{
${ }^{1}$ Read hefore the 11 th Annual Meeting of the Association for Academic Surgery, Seattle, Washington, November 4, 1977.

${ }^{2}$ Supported in part from Michigan Heart Association and Michigan Kidncy Foundation Grants.
}

and small intervening branches occluded with ligatures. Blood within the isolated arterial segment was aspirated through a polyethylene catheter inserted into the lumen at the occluding loop. In experimental arteries, vessels were infused with a thrombin-gelatin mixture under a pressure of $100 \mathrm{~mm} \mathrm{Hg}$. This material was prepared by adding $0.5 \mathrm{ml}$ of bovine thrombin ( $5000 \mathrm{NIH}$ units) to $5 \mathrm{ml}$ of freshly constituted $10 \%$ gelatin solution. After 5 min, the thrombin-gelatin was aspirated. Blood flow was restored following irrigation of the vessel with balanced salt solution. The contralateral iliofemoral artery was treated as a control. An identical protocol was used except for substitution of balanced salt solution for the thrombingelatin mixture.

Both control and experimental iliofemoral arterial segments were removed simultaneously for study 1 week to 1 year later. India ink was infused at physiologic pressures into both arterial segments for demonstration of vasa vasorum prior to their harvest.

Excised vessels were immediately fixed in a $2.5 \%$ cocodylate-buffered glutaraldehyde solution. Transmural tissue specimens, approximately $1.0 \mathrm{~mm}^{2}$, were fixed for $3 \mathrm{hr}$. Tissues for scanning electron microscopy (SEM) were dehydrated, critical point dried, and coated with gold vapor. Tissues for transmission electron microscopy (TEM) were washed in cocodylate buffer for 6 to $8 \mathrm{hr}$ and postfixed in $2 \% \mathrm{OsO}_{4}$ for 2 hr. Specimens were stained en bloc with $0.5 \%$ uranyl acetate in malcic acid at pH 5.2. 
Following ethanol dehydration, the tissue was embedded in Epon 812. Thin sections were stained with uranyl acetate-lead citrate and coated with carbon. Arterial segments prepared for light miscoscopy were processed in a standard manner and stained with hematoxylin-eosin, Verhoeff, or Masson stains.

Cellular and subcellular characteristics of the experimental and control arterial walls were compared. Specimens were examined within the first week (three subjects), from 2 to 4 months (seven subjects), from 4 to 7 months (four subjects), and at 12 months (two subjects), postinfusion. Particular care was directed toward examination of those areas most typical of the entire arterial segment.

\section{RESULTS}

Thrombin-gelatin infusions effectively obliterated nearly all vasa vasorum (Fig. 1A). Reappearance of these nutrient vessels was very unusual during the course of the study. Conversely, normal vasa vaso- rum, documented with India ink infusions, were present in all control specimens (Fig. 1B). Intraluminal thrombus and perivascular or adventitial inflammation were not encountered in either experimental or control vessels. Gross morphologic alterations, in the form of increased vessel wall thickness, were observed only in the experimental arterial segments. This change became more obvious in vessels examined late following thrombin-gelatin infusion.

Control arteries, irrespective of time studied, exhibited normal cellular and subcellular features. Endothelial cells, subendothelial structures of the intima, as well as adventitial tissues appeared normal. Fibroblasts within the medial tissues were few in number and also normal in appearance. In particular, abnormalities of medial smooth muscle were not observed. Smooth muscle cells of control segments, arranged in regular strata, exhibited certain common features including: close apposition of cytoplasmic processes to neighboring cells, an ovoid nucleus, having deep
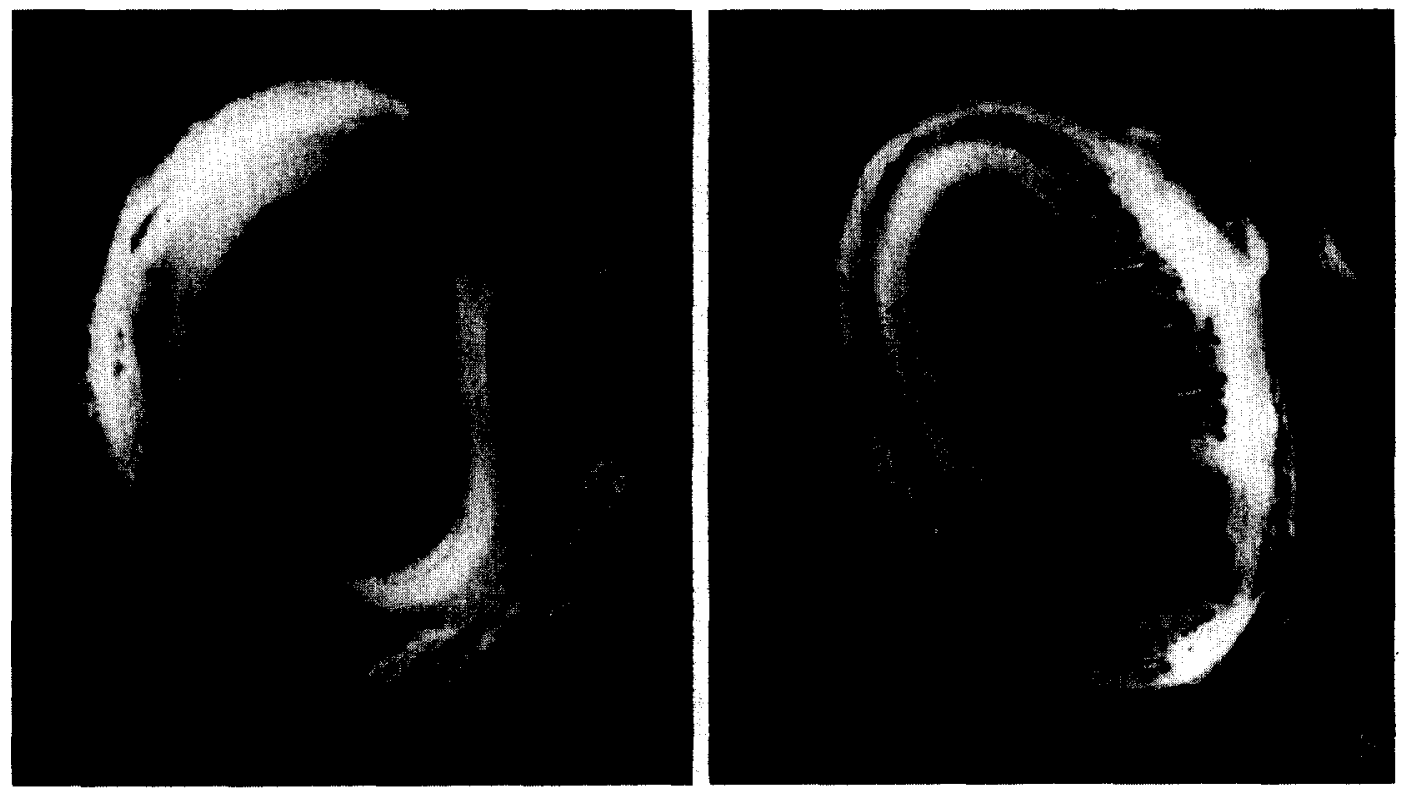

FIG. 1. (A) Experimental specimen of canine ileofemoral artery 200 days postinfusion of thrombingelatin. Vasa vasorum were not demonstrated following India ink infusion in any arterial segments treated in this manner. (B) Control specimen of contralateral ileofemoral artery following infusion of buffered salt solution. India ink-filled vasa vasorum (arrows) are identified at the media-adventitial junction. 
indentations and convolutions, surrounded by cellular organelles (mitochondria, rough endoplasmic reticulum, Golgi complexes, and free ribosomes), orderly appearing myofilaments, predominantly parallel to the longitudinal cell axis, radiodense bodies along the cell wall denoting myofilament attachment to the plasma lamina, as well as basal laminae and peripheral micropinocytotic vesicles along the plasma lamina.

Experimental arterial segments having occluded vasa vasorum exhibited distinct morphologic abnormalities. Derangements were less if any vasa vasorum persisted. Although serial sections at different time periods from individual segments were not obtained, the process leading to morphologic alterations appeared anatomically covert the first few months. It was not until
3 months postinfusion that marked changes in smooth muscle with increases in extracellular connective tissue and the appearance of myofibroblasts became obvious.

The intima in experimental vessels was usually unaltered. Occasionally, subendothelial derangements were substantial, yet endothelial cells were invariably maintained (Fig. 2). In vessels having intimal changes, excessive amounts of collagen, elastic tissue, and amorphous ground substances were common. Migratory smooth muscle cells were infrequent accompaniments of the former.

Medial abnormalities were the most obvious consequence of vasa vasorum occlusion. Smooth muscle and connective tissue derangements were clearly present 3 months postinfusion, being most marked in

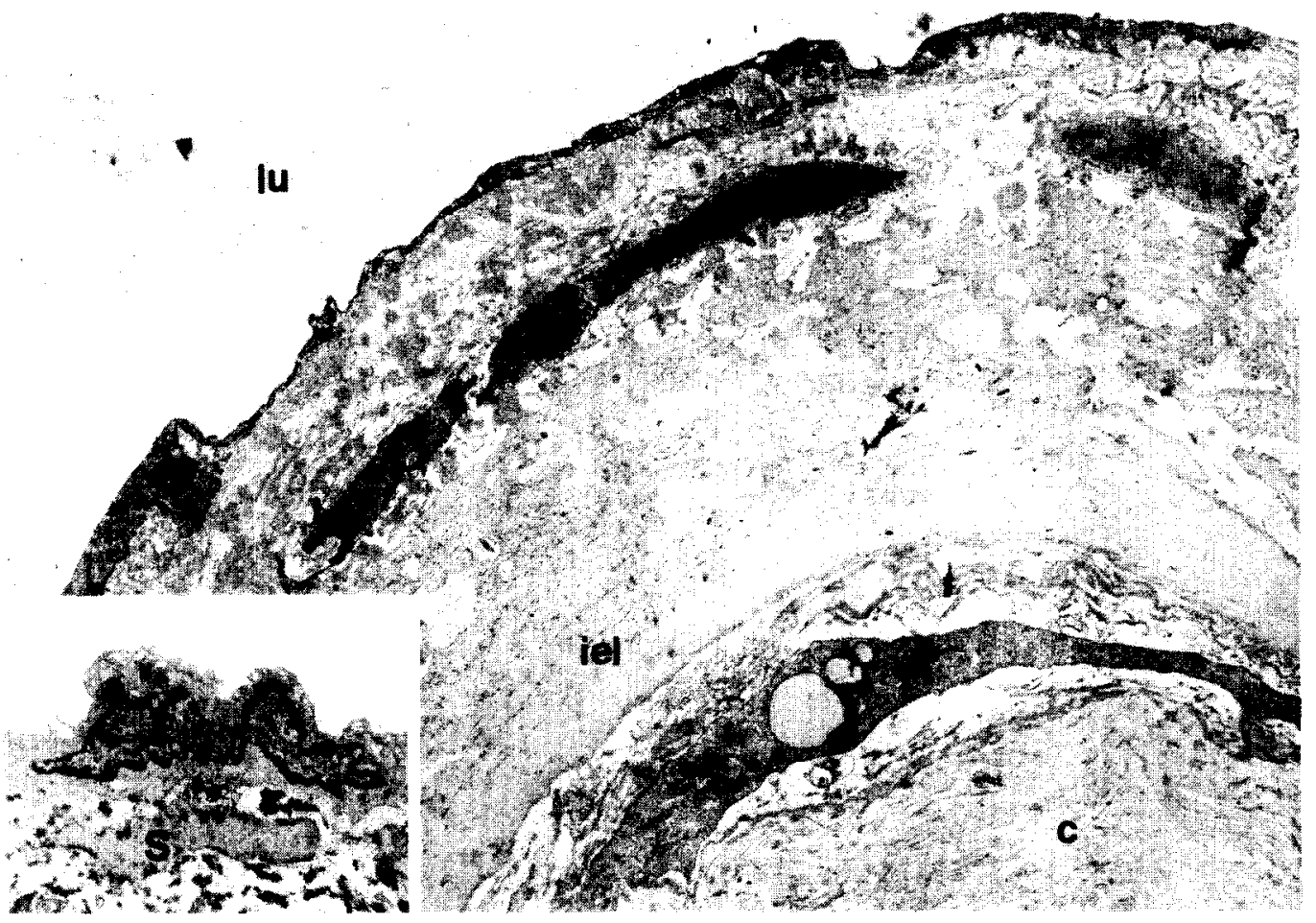

FIG. 2. Thrombin-gelatin-prepared arterial segment 200 days postinfusion. Endothelial cell (E) integrity is maintained, although microvilli are sparse. Smooth muscle cells (S) appear mummified (see text). Elastic tissue has an infiltrative appearance within diffusely distributed collagen (c) fibers and is in continuity with the internal elastic lamina (iel). Lumen (lu). Original TEM $\times 2500$. Inset: representative endothelial cell (E) depicting normal cell contour and subcellular organelles. Smooth muscle cell (S). Original TEM $\times 15,000$. 
tissues examined at 1 year. Cellular pleomorphism appeared more severe in the periphery of the media than in tissues nearer the lumen. A continuum, from active smooth muscle cells to distinctly abnormal myofibroblasts (Fig. 3-7), was observed in the media of the experimental vessels.

Two smooth muscle cell abnormalities were recognized. Rarefication proved to represent an early type of smooth muscle degeneration, characterized by areas within the cytoplasm devoid of myofilaments, swollen mitochondria, vacuoles, and basal lamina indistinctness. The second type abnormality, mummification, seemingly represented a more advanced form of cell degeneration. It was characterized by picnotic nuclei, perinuclear vacuolation, loss of juxtanuclear organelles, and large peripheral vacuoles with indistinct myofilaments. Whereas rarefication may represent a reversible process, mummification is believed a reffection of irreparable cell damage. Smooth muscle cell fragmentation with frank necrosis was occasionally observed in these specimens but was not a dominant feature.

Myofibroblasts were a common finding in vessels having occluded vasa vasorum. Morphologic characteristics of these cells ranged from those of modified fibroblasts to that of atypical smooth muscle cells. In contrast to fibroblasts, whose nuclei were

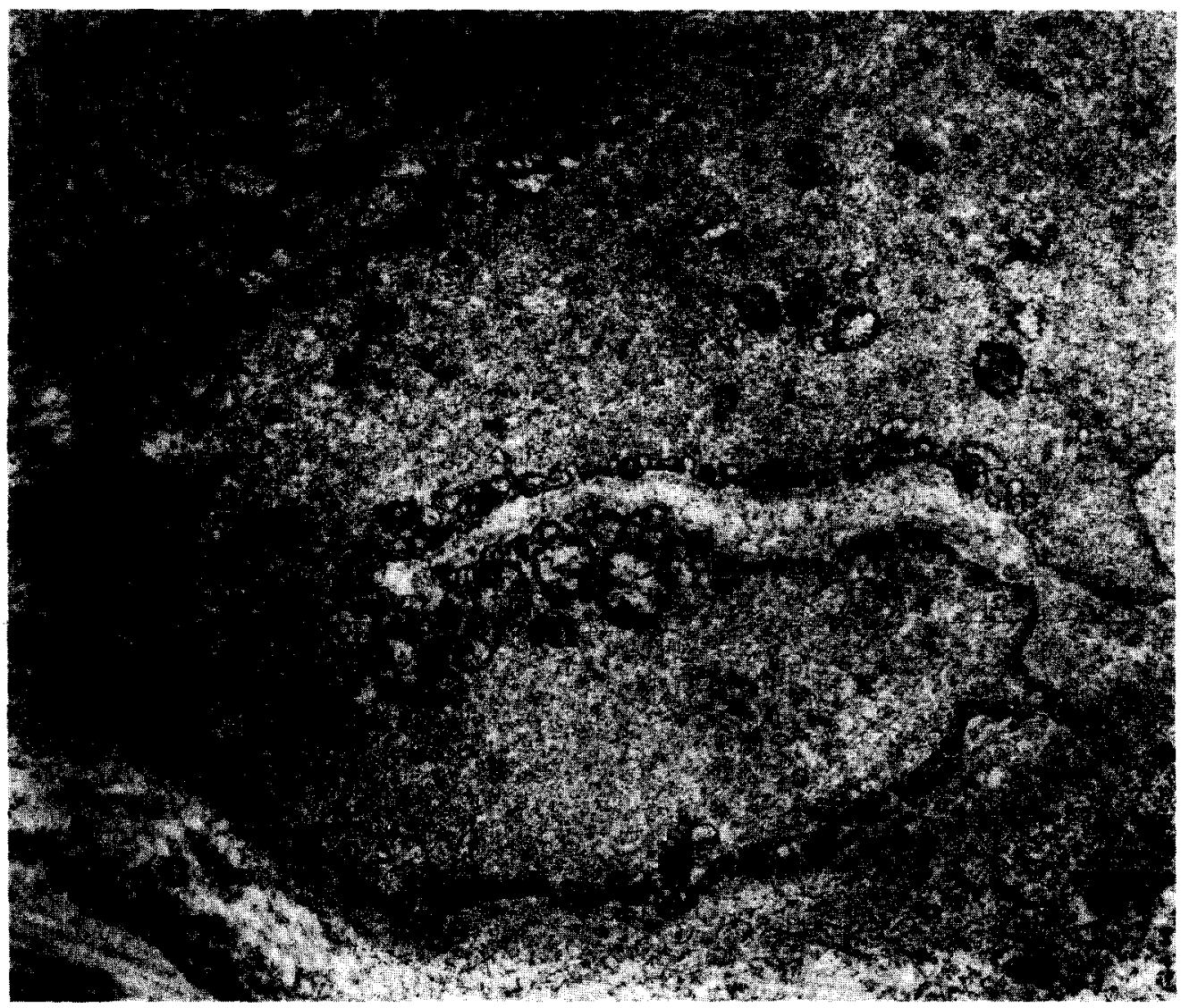

FIG. 3. Smooth muscle cell (S) within media of thrombin-gelatin-infused artery at 200 days. Areas devoid of myofilament are scattered throughout the cytoplasm (arrows) and are characteristic of rarefication (see text). Mitochondria (m) are swollen. Intracytoplasmic vacuoles $(v)$ are present, but micropinocytotic vessicles $(\mathrm{mp})$ are reduced in number. Collagen (c). Original TEM $\times 15,000$. 


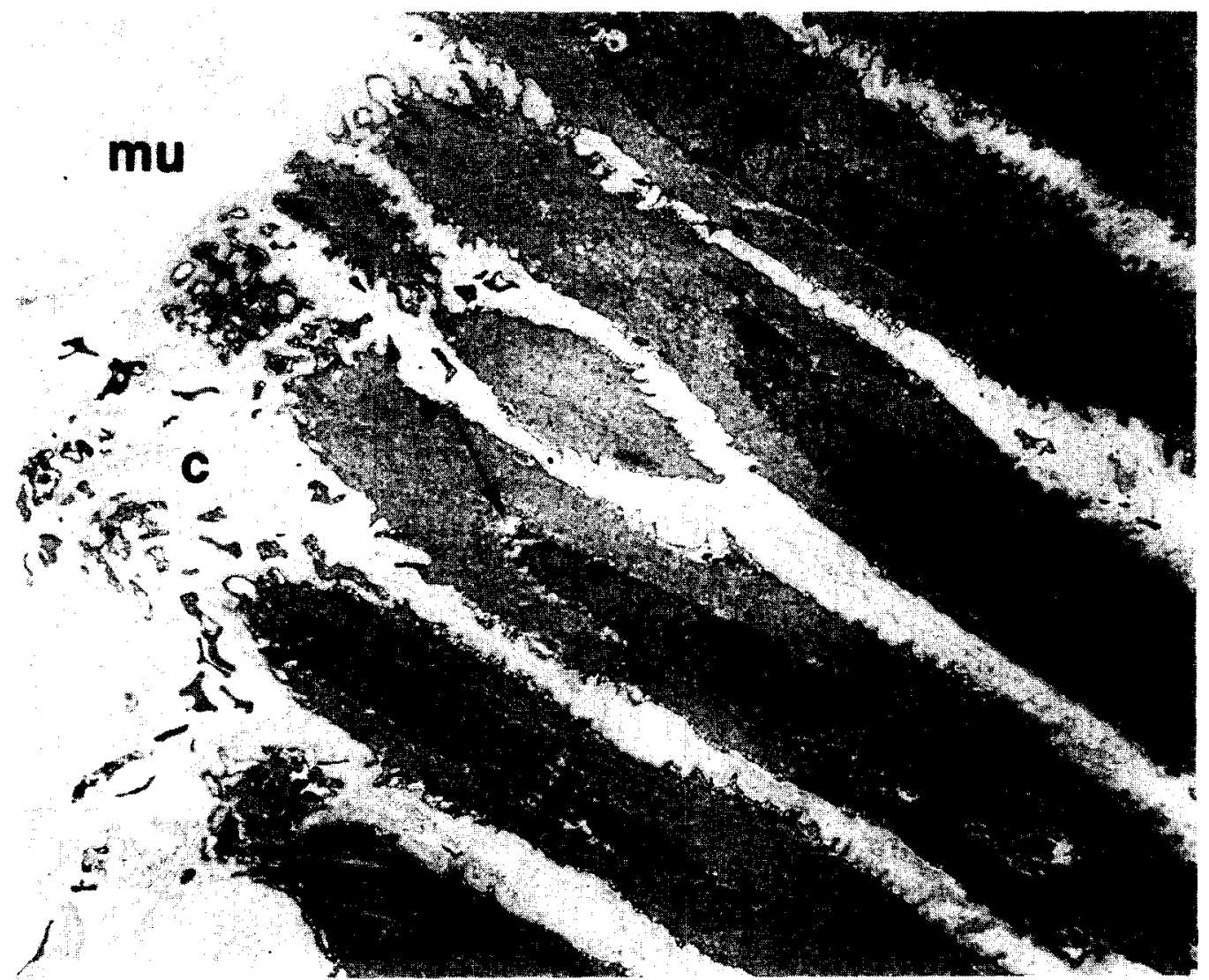

Fig. 4. Orderly stratum of medial smooth muscle cells (S) 200 days postthrombin-gelatin infusion. Myofilaments exhibit homogeneous indistinct features characteristic of mummification. Perinuclear vacuolation (arrow), loss of subcellular organelles, and peripheral vacuolation with confluence of micropinocytotic vesicles are additional features typical of this degenerative state. Moderate accumulation of ground substance and connective tissue elements surround these cells. Collagen (c). Homogeneous mucoid substance (mu). Original TEM $\times 3000$.

usually smooth and ovoid in shape, the myofibroblast nucleus was invariably convoluted with numerous indentations and evaginations. In this respect myofibroblasts resembled contractile smooth muscle cells (Figs. 6 and 7). Other features distinguishing myofibroblasts from fibroblasts were more juxtanuclear loci of cytoplasmic organelles and the existance of cytoplasmic filaments. Basal lamina of myofibroblasts were often indistinct.

The adventitia of vessels subjected to thrombin-gelatin infusions appeared relatively normal and, excepting an absence of vasa vasorum, could not be differentiated from control arteries. Although disrupted vasa vasorum were observed in 1-week studies, later examination failed to document restoration of normal nutrient blood vessels.

\section{DISCUSSION}

The pathogenesis of arterial fibrodysplasia has been an elusive subject since this disease entity was first recognized more than $\mathbf{4 0}$ years ago. Medial fibroplasia is the most common form of arterial dysplasia [8]. This type of dysplasia represents a continuum. Lesions vary from focal stenoses to multiple constricting lesions in series with intervening aneurysmal out- 


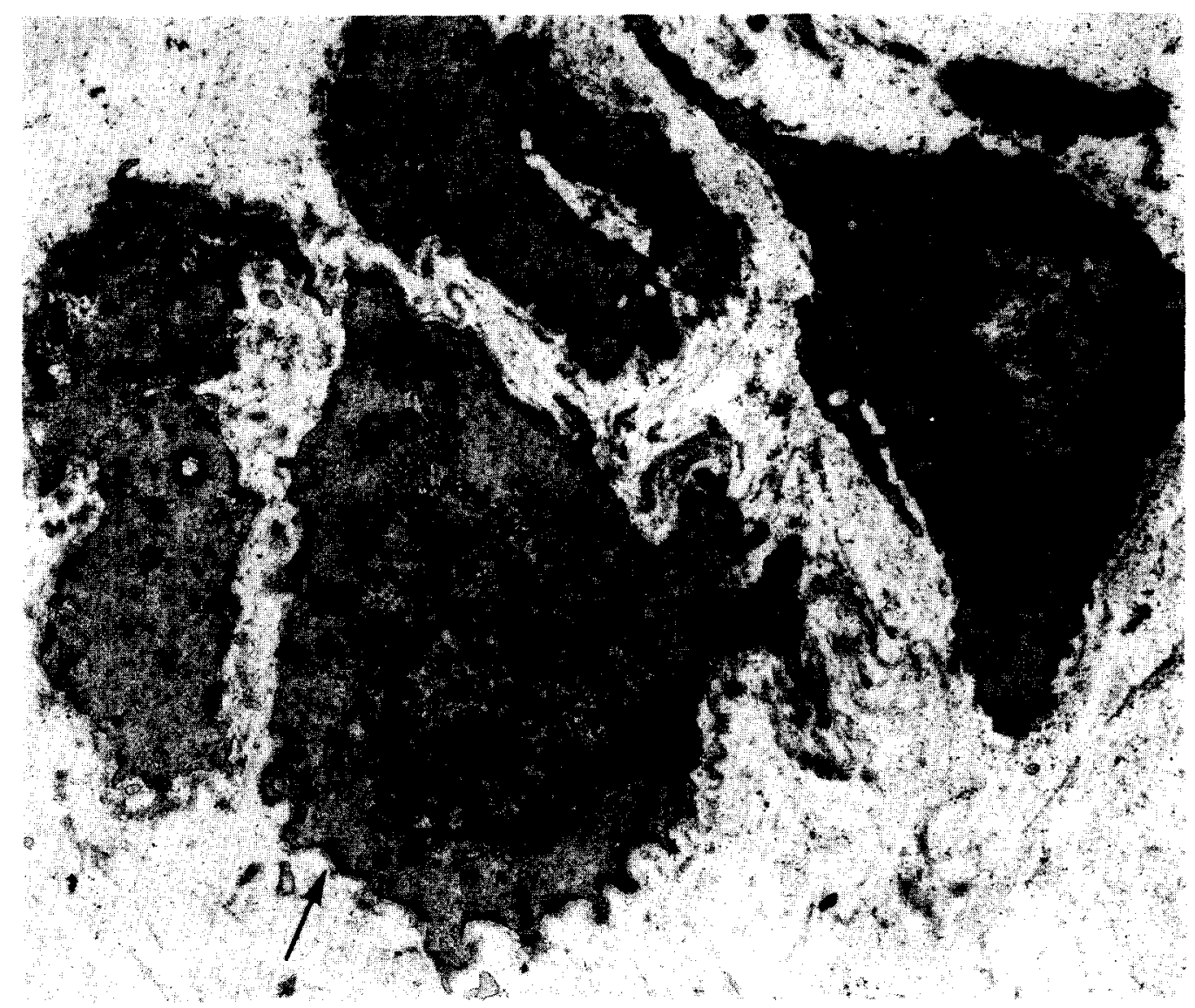

FIG. 5. Smooth muscle cells (S) with active rough endoplasmic reticulum (rer), Golgi complex (gc), intact basal lamina (arrow), and mitochondria $(\mathrm{m})$. Original TEM $\times 8000$.

pouchings. Two variants of medial fibroplasia exist. A peripheral form is manifest by dense fibroproliferative changes with excesses in collagen, increased ground substance, and loss of smooth muscle in the outer media. Relatively little involvement of the inner media occurs. The second form, diffuse medial fibroplasia, is charcterized by more severe disruptions of the media architecture with loss of most recognizable smooth muscle. Medial thinning, alternating with accumulations of fibrous tissue, occurs most commonly with diffuse disease.

In contradistinction to other types of arterial dysplasia, mounting evidence supports the likelihood that several factors contribute to the evolution of medial fibroplasia. Particularly suspect are: (1) mural ischemia, being enhanced by the paucity of vasa vasorum found in vessels most commonly affected, (2) unusual mechanical stresses on arteries most susceptible to fibrodysplastic changes, and (3) hormonal influences, refiected by the fact that more than $90 \%$ of patients exhibiting medial fibrodysplasia are female.

Although the present investigation was directed at assessing mural ischemia as a cause of medial fibroplasia, other factors should not be ignored. In fact, two earlier studies have provided indirect support to the mechanical and hormonal hypotheses. Specifically, Leung, et al. demonstrated that repeated stretching of smooth muscle cells in culture potentiated synthesis of collagen and certain acid mucopolysacchariades [2]. Similarly, Ross and Klebanoff were among the first to demonstrate estro- 


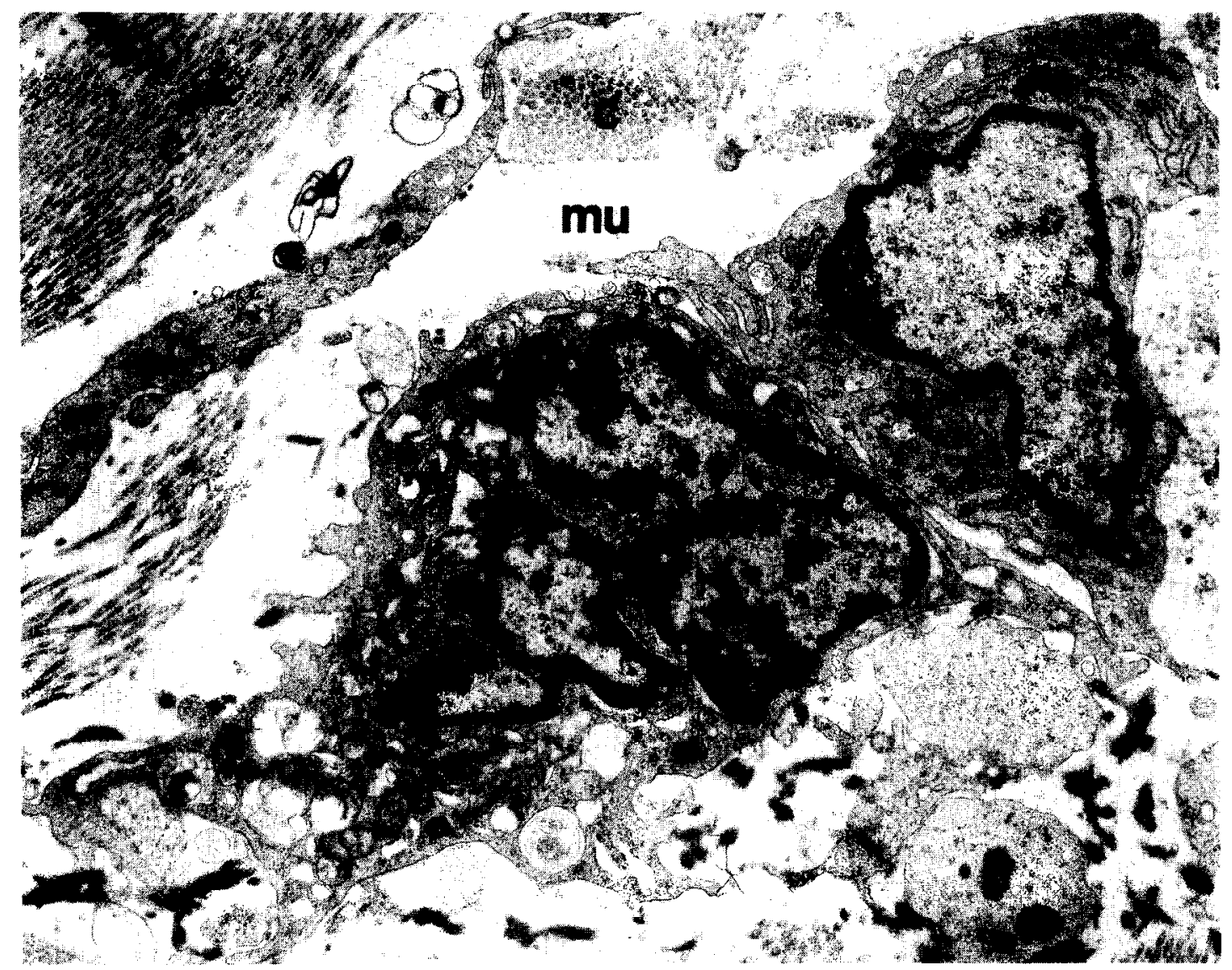

FIG. 6. Myofibroblast (MF) exhibiting features of both smooth muscle and fibroblast cells. Prominent nuclei are indented and convoluted. Myofilaments appear in the peripheral cytoplasm. Incomplete basal lamina and diffuse distribution of subcellular organelles characterize this cell. Collagen (c). Homogeneous mucoid substance (mu). Original TEM $\times 15,000$.

gen stimulation of smooth muscle cells to produce extracellular connective tissue proteins in vivo [6]. Complex investigations, designed to measure the influence of hypoxia on smooth muscle cells previously stimulated to produce collagen, elastin, and ground substances have not been conducted.

Dominant pathology encountered in the present study was that of the myofibroblast cell. Although speculative, the source of these cells appeared to be vascular smooth muscle cells. Ross demonstrated the capability of smooth muscle cells to synthesize and secrete extracellular proteins in vitro [7]. The stimulus for smooth muscle cells to drastically alter their morphologic appearance and function is un- known. Mural ischemia with tissue hypoxia is assumed the inciting event in the present study, but altered tissue $\mathrm{pH}$, accumulation of metabolites, or some other factors may be more important. No data were evident from the current investigation to suggest that myofibroblasts evolved from proliferation of previously dormant mesenchymal cells. This does not exclude such a possibility. Indeed, medial smooth muscle cells are considered by Wissler to represent multifunctional mesenchymal cells [9]. Gabbiani et al. on the other hand, view the myofibroblast as a contractile fibroblast rather than a modified smooth muscle cell [1].

Impairment of vascular wall blood supply 


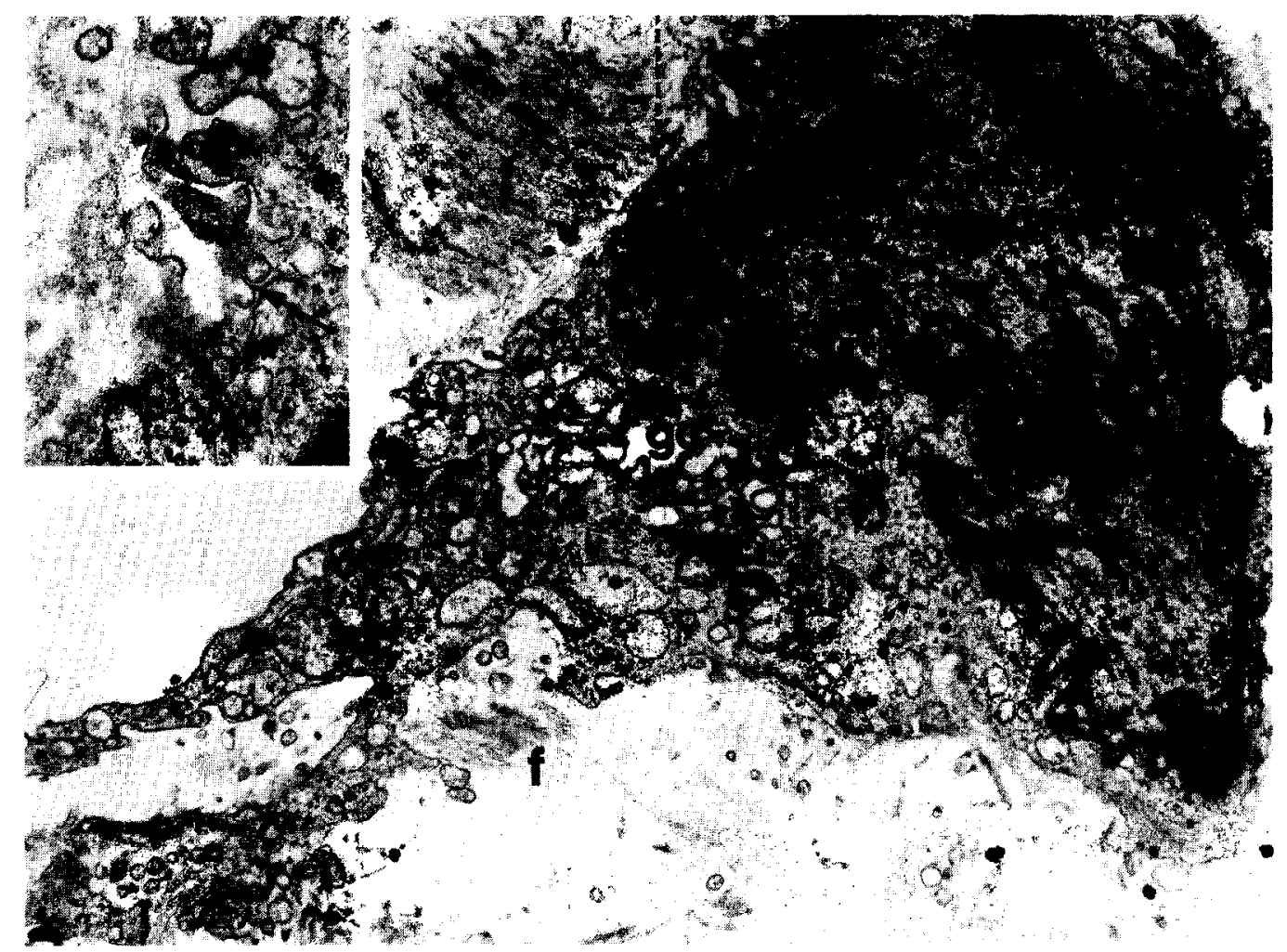

FIG. 7. Myofibroblast (MF) in secretory state typical of fibrodysplastic process following vasa vasorum occlusion. Dilated cisternae and prominent Golgi complexes (gc) reflect active secretion. Fibrous bundles (f). Mitochondria (m). Original TEM $\times 15,000$. Inset: Extracellular deposition of proteinaceous matter (arrow) by active exopinocytosis. Original TEM $\times 60,000$.

as a cause of arterial medial fibrodysplasia has received indirect support from a number of earlier studies. Obliteration of vasa vasorum using a thrombin-containing mixture has been described by Nakata [5], Nakata and Shionoya [4]. Although their studies related to the aorta, their light microscopic descriptions of medial changes paralleled those of the current study. Clinical recognition of the peripheral form of medial fibroplasia [8], and the observation that altered smooth muscle cells and myofibroblasts were more common in the outer media of vessels subjected to thrombingelatin infusions, may be a reflection of the degree of vessel wall hypoxia. Obliteration of vasa vasorum should have a greater effect in reducing oxygenation and nourishment of cells in the outer media, in com- parison to those near the vessel lumen. Wolinsky and Glagov documented the constancy of the avascular inner media in aortae of different mammals [10]. In this regard, limitations in transluminal passage of nutriments may be important in peripheral medial fibroplasia. This would account for inner medial smooth muscle preservation and development of dysplastic disease in deeper layers. The duration and exact degree of ischemia necessary to stimulate myofibroblasts are unknown. Madden, et al. have demonstrated these cells in tissues subjected to limited hypoxic events [3]. They documented active contractile processes in musculature occurring long after inciting stimuli had been removed. In many respects, in the current study the lack of early morphologic changes following vasa 
vasorum occlusion followed by the late appearance of myofibroblasts parallels their experience.

Ultrastructural characteristics of experimental arterial medial fibrodysplasia induced by vasa vasorum occlusion in the current investigation bear a striking resemblance to human fibrodysplastic lesions. Modification of arterial smooth muscle cells to more primitive functioning myofibroblasts appears to be a major if not the primary pathologic feature of this fibroproliferative disease.

\section{REFERENCES}

1. Gabbiani, G., Majno, G., and Ryan, G. B. The fibroblast as a contractile cell: The myo-fibroblast. In E. Kulonen and J. Pikkarainen (Eds.), Riology of Fibroblast, pp. 139-154. Academic Press, New York, 1973.

2. Leung, D. Y. M., Glagov, S., and Mathews, M. B. Cyclic stretching stimulates synthesis of matrix components by arterial smooth muscle cells in vitro. Science 191: 475, 1976.
3. Madden, J. W., Carlson, E. C., and Hines, J. Presence of modified fibroblasts in ischemic contracture of the intrinsic musculature of the hand. Surg. Gynecol. Obstet. 140: 509, 1975.

4. Nakata, Y., and Shionoya, S. Vascular lesions due to obstruction of the vasa vasorum. Nature (London) 212: 1258, 1966.

5. Nakata, Y. An experimental study on the vascular lesions caused by obstruction of the vasa vasorum. Japan. Circ. J. 31: 275, 1967.

6. Ross, R., and Klebanoff, S. J. The smooth muscle cell. I. In vivo synthesis of connective tissue proteins. J. Cell Biol. 50: 159, 1971.

7. Ross, R. The smooth muscle cell. II. Growth of smooth muscle in culture and formation of elastic fibers. J. Cell Biol. 50: 172, 1971.

8. Stanley, J. C., Gewertz, B. C., Bove, E. L., Sottiurai, V., and Fry, W. J. Arterial fibrodysplasia. Histopathologic character and current etiologic concepts. Arch. Surg. 110: 561, 1975.

9. Wissler, R. W. The arterial medial cell, smooth muscle or multifunctional mesenchyme? J. Athernscler. Res. 8: 201, 1968.

10. Wolinsky, H., and Glagov, S. Nature of species differences in the medial distribution of aortic vasa vasorum in mammals. Circ. Res. 20: 409, 1967. 